\title{
Investigating the Acquisition Order of English Restrictive Relative Clauses: Evidence from Egyptian EFL Learners
}

\section{* Dr. Inas Hussein Hassan}

\begin{abstract}
The research area of relative clauses (RCS) has been a significant topic in the field of language acquisition due to the complex syntactic structures of $R C s$ and the difficulties they pose to language learners in processing them. The aim of the present study is to investigate the learnability of English restrictive RCs by Egyptian adult EFL learners, thus testing four different hypotheses on the acquisition of RCs in English: Keenan's (1975) Relativized Subject Accessibility; Kuno's (1975) Perceptual Difficulty Hypothesis (PDH); Sheldon's (1974) Parallel Function and Hamilton's (1994) Subject-Object Hierarchy Hypothesis (SOHH). A total of 61 Egyptian Englishmajor first-year college students participated in the study. In addressing this objective, the researcher employed two tests: a Sentence Combination Production Test (SCPT) and a Grammaticality Judgement Test (GJT) in order to examine the learners' knowledge of English RCS. In the SCPT, the participants were instructed to combine two sentences together using a suitable relative pronoun and in the GJT, they were asked to judge the grammaticality of the given sentences. The results reveal that Egyptian EFL learners might not be fully aware of the formulation rules of RCs in English (total mean $=56.6 \%$ in the SCPT and $72.4 \%$ in the GJT). Findings of the study show that for Egyptian learners, SS and OS relative clause types would be easier to acquire than SO and $0 O$ types. The most marked types of errors made by Egyptian learners were inappropriate positioning of the $R C$, use of wrong relative pronoun and repetitive use of resumptive pronouns where they are not called for. The concluding section of the paper ends with some pedagogical implications and recommendations for future research.

Key words: Relative Clauses - Restrictive/ Non-restrictive Relative Clauses Relativized Subject Accessibility - Perceptual Difficulty Hypothesis Parallel Function - Subject-Object Hierarchy Hypothesis
\end{abstract}

Lecturer and Vice Dean of Graduate Studies

College of Language and Communication (CLC)

Arab Academy for Science, Technology and Maritime Transport (Alexandria) 


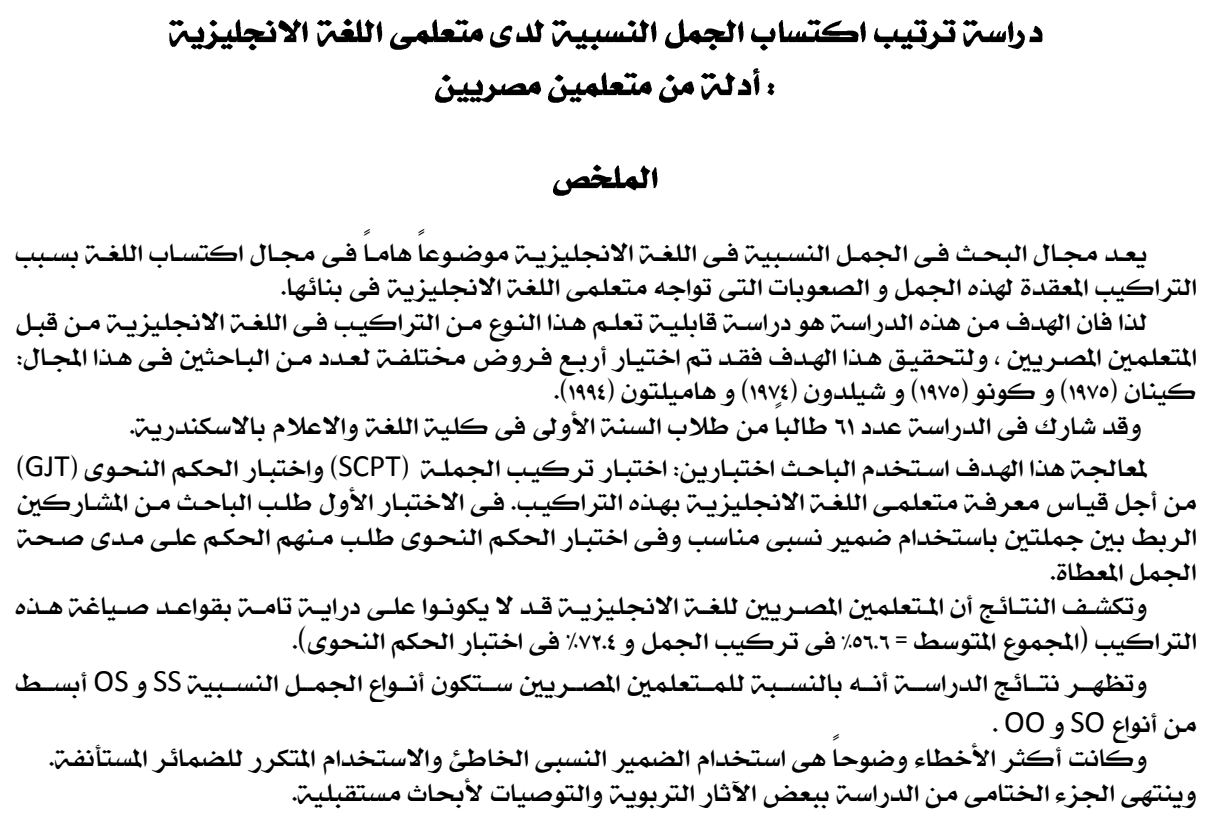

\section{Introduction}

The research area of relative clauses (RCs) has attracted the attention of many educators and researchers in the field of second language acquisition due to the complex syntactic behavior of RCs compared to other structures and the difficulties that language learners encounter in processing them (Abdolmanafi \& Rahmani, 2012; Gao, 2014). In spite of the fact that RCs are syntactic structures that are common across all languages, they are expressed differently in each language. As a result, the diverse syntactic structures existing in different languages might pose difficulties to learners attempting to comprehend these grammatical constructions. Therefore, due to their complex nature, a number of studies have investigated the acquisition of this phenomenon by EFL learners (Khan \& Al-Namer, 2017).

Additionally, several hypotheses have been proposed in order to account for the acquisition of RCs by EFL learners. Among these, the three hypotheses that have received most attention are Keenan and Comrie's (1977) Noun Phrase Accessibility Hierarchy Hypothesis (NPAH), Kuno's (1974) Perceptual Difficulty Hypothesis (PDH) and Hamilton's (1994) 
Subject-Object Hierarchy Hypothesis (SOHH). Much research has been conducted to verify these hypotheses in both first and second languages. There were noticeable variations among such research studies not only in terms of the focus of investigation but also in terms of the participants and the data collection instruments employed by the researchers (Gao, 2014).

However, a survey of the literature on the acquisition of RCs has revealed that the acquisition of this phenomenon by Arab-speaking EFL learners has been given little attention (Khan \& Al-Namer, 2017, p. 193). Hence, the purpose of this study is to address this gap by exploring the learnability of English RCs by Egyptian adult EFL learners. The study purports to answer the following research questions:

1. What is the difficulty order of the four types of English restrictive RCs: SS, SO, OS and OO by Egyptian EFL learners?

2. To what extent do the results of the study lend support to any of the different hypotheses of RC acquisition: Relativized Subject Accessibility, Perceptual Difficulty Hypothesis, Parallel Function and Subject-Object Hierarchy Hypothesis?

3. What are the most marked errors made by Egyptian EFL learners in the acquisition of English restrictive RCs?

In this way, the present study attempts to test the hypotheses of four language researchers- Kuno (1975), Keenan (1975), Sheldon (1974) and Hamilton (1994) with regard to the sequence of acquisition of four types of RCS in English- SS, SO, OS and OO. It is an attempt to determine whether there is an order of difficulty or accessibility among the four types of RCs produced by Egyptian learners which is in agreement with any of the hypotheses produced by the aforementioned researchers. Furthermore, it explores the main difficulties that learners encounter throughout the process of acquiring RCs and attempts to account for them. A total of 61 Egyptian adult EFL learners have participated in this study. The researcher employed a Sentence Combination Production Test (SCPT) and a Grammaticality Judgement Test (GJT) in order to measure the ability of the participants to comprehend and produce RCs in English.

$$
\text { rio }
$$


The paper is structured as follows: the first part gives theoretical background information about RCs, the most common hypotheses on RCs in the literature and a brief survey of previous studies on the acquisition of English RCs; the second part presents the methodology of the study: participants, data collection instruments and statistical analysis, and the third part outlines the main results. Finally, the paper concludes with some pedagogical implications and recommendations for future research.

\section{Literature Review}

\subsection{Relative Clauses: Definition and Types}

The acquisition of RCs has been a significant area of research in linguistic and psycholinguistic fields of study. In fact, this complex grammatical construction has been studied extensively by many researchers in both first and second language acquisition due to its complex syntactic structures and the difficulties it poses to EFL language learners (Abdolmanafi \& Rahmani, 2013; Gao, 2014). It can be argued that the main difficulty in RC acquisition stems from the fact that learners attempt to understand the embedded clause on the one hand and to track the main clause on the other hand. The main function of RCs is giving more information about the noun head. Such a function is essential for communication; hence, mastering RCs by children and EFL/ESL learners alike is vital (Alotaibi, 2016, p. 57). Previous studies related to RC acquisition in $L 2$ can be characterized by three tracks of research: the first examining the "implicational" universals of language; the second investigating the effects of instruction on RC acquisition and the third exploring the cross-linguistic influences on RC acquisition in L2 (Chang, 2004).

The RC construction is considered a universal phenomenon since it is "ubiquitous" to all languages; however, it appears in different forms. Some languages make use of relative pronouns and complementizers (e.g. English); some may use pre-verbal relative pronouns in conjunction with post-verbal resumptive pronouns in an encasing construction (e.g. Arabic); whereas others tend to use case-marked relative pronouns to relativize the head noun; e.g. German (Khan \& Al-Namer, 2017, p. 193). It is also 
worth noting here that English is a Right Branching Direction (RBD) language in which RCs appear to the right of the head noun. In contrast, other languages such as Chinese rely on a Left Branching Direction (LBD) in which RCs pre-modify the head (Abdolmanafi \& Rahmani, 2013).

An English RC can be defined as a subordinate or dependent clause which is often referred to as an adjective clause. It acts as an adjective modifying a noun or a noun phrase in the matrix clause by making it more specific or by giving additional information about a person, thing or idea. A $\mathrm{RC}$ should be located immediately after the noun it modifies. It typically starts with a relative pronoun such as who, whom, which, that and whose. The selection of the pronoun depends on the noun which the $\mathrm{RC}$ refers to and the type of the RC. A relative pronoun can have different functions in a sentence; e.g., subject, direct object, indirect object, object of a preposition (Abdolmanafi \& Rahmani, 2013; Gao, 2014; Alroudhani, 2016; Khan \& Al-Namer, 2017).

English RCs can be categorized into two types: restrictive and nonrestrictive. This depends upon the necessity of information that a RC provides. Whereas a restrictive RC provides essential information to define or clarify the noun or noun phrase that it modifies, a non-restrictive RC provides additional information. Following are illustrative examples of the two types of RCs:

a) The woman who lives next door is a famous writer

b) Ms. John, who lives next door, is a famous writer

In example (a), the RC 'who lives next door' is used to make the noun head in the main clause more specific; i.e. without this information, the meaning of the sentence would not be clear to the listener or reader. On the other hand, in example (b), the RC 'who lives next door' only gives additional information since 'Ms. John' itself conveys enough information about the person. According to Izumi, restrictive RCs are more commonly used than non-Restrictive ones (as cited in Abdolmanafi \& Rahmain, 2012, p. 30). Hence, in the present study, the focus will be on restrictive RCs.

Additionally, previous studies on RCS in SLA literature has categorized English RCs into four main types: SS where both the head noun to be relativized and the gap are in the subject position; SO where 
the head noun is the subject and the gap is the object; OS where the head noun is the object and the gap is the subject; and $\mathrm{OO}$ where both the head noun and the gap are in the object position (Hamilton, 1994). Examples of these types are shown as follows:

1. The student who got an $A$ is a friend of mine. (SS)

2. The house in which Jack lives is very old. (SO)

3. Sally likes the dog that bit John's leg. (OS)

4. I know the woman who(m) you are looking for. (OO)

\subsection{Hypotheses on RC Acquisition}

In their attempts to define a potential natural sequencing of RCs, researchers put forward a number of hypotheses on language universals. These are Noun Phrase Accessibility Hierarchy (NPAH), Relativized Subject Accessibility, Perceptual Difficulty Hypothesis (PDH), Parallel Function and Subject-Object Hierarchy Hypothesis (SOHH).

\subsubsection{Noun Phrase Accessibility Hierarchy (NPAH)}

Keenan and Comrie (1977) established a universal implicational relativization hierarchy (subject $>$ direct object $>$ indirect object $>$ object of preposition $>$ genitive $>$ object of comparison) which reflects the acquisition order of the different types of RCs. According to the NPAH, if a language can form RCs on a given position in the hierarchy, it can also form RCs on all positions higher in the hierarchy. For example, if a language can form RCs on OPREP, it can also form RCs on SU, DO and IO but not necessarily on GEN or OCOMP. This hypothesis reflects the natural order of acquisition and it predicts that RCs formed on the subject are easiest to learn whereas those on the object of a comparative are the most difficult. Following are examples of each of the six types of RCs:

1. Noah's sister who lives in France is a teacher. (Subject)

2. I carried the child whom the dog bit. (Direct object)

3. The man to whom she gave the flower is very handsome. (Indirect object)

4. The house in which Jack lives is very old. (Object of adposition) 
5. The student whose exam the teacher marked is very intelligent. (Genitive)

6. The bike than which the car is faster was stolen yesterday. (Object of comparison)

Much of the research on RC acquisition in L2 has been conducted to test Keenan and Comrie's NPAH on language acquisition. Following such extensive studies, a number of research studies were conducted in order to identify the difficulties that EFL with different backgrounds encounter (e.g. Abdolmanafi \& Rahmani, 2013; Gao, 2014; Alotaibi, 2016; Khan \& Al-Namer, 2017).

\subsubsection{Relativized Subject Accessibility}

Keenan (1975) asserted that relativized subjects are more accessible than relativized objects. Thus, he argued that SS and OS types should be easier than $\mathrm{SO}$ and $\mathrm{OO}$ types.

\subsubsection{Perceptual Difficulty Hypothesis (PDH)}

Based on the limitations of the human memory system, Kuno (1975) claimed that sentences with center embedding are perceptually more difficult to process than sentences with right branching. This is due to the fact that center embedding interrupts the processing of the matrix clause whereas right embedding does not. Therefore, he argued that OS and OO types should be easier than SS and SO types:

$\mathrm{OS} / \mathrm{OO}>\mathrm{SS} / \mathrm{SO}$

where > means "is easier than" and / means "as difficult as".

\subsubsection{Parallel Function}

In this hypothesis Sheldon (1974) argued that RCs having the same function as the head noun are easier to process. Thus, she claimed that SS and OO should be easier than SO and OS types.

\subsubsection{Subject-Object Hierarchy Hypothesis (SOHH)}

Hamilton's (1994) SOHH has received much attention. This hypothesis is based on the notion of processing discontinuity. The $\mathrm{SOHH}$ proposes an implicational relationship between the 
four types of RCS, namely OS, OO, SS and SO. In each of these labels, the first code refers to the head noun as either subject (S) or direct object $(\mathrm{O})$ of the matrix clause and the second code refers to the role of the NP target of relativization within the RC. Accordingly, the $\mathrm{SOHH}$ predicts the following difficulty order:

OS $>$ OO/SS $>$ SO

According to this hypothesis, the number of discontinuities determines the level of difficulty. Therefore, the OS type should be the easiest to acquire since it contains only one discontinuity. OO and SS types are of equal difficulty since they contain two discontinuities. SO type is assumed to be the most difficult since it contains three discontinuities.

The following section briefly reviews a number of recent research studies that concentrated on investigating the acquisition hierarchy of RCs by EFL learners belonging to different linguistic backgrounds.

\subsection{Previous Studies on the Acquisition of English RCs}

Abdolmanafi and Rahmani (2012) investigate the acquisition of RCs by a number of 78 Persian-speaking EFL learners of a high intermediate proficiency level in English using a Sentence Combination Test. The researchers attempt to explore the sequence of acquisition of four types of RCs in English - OS, OO, SS and SO by testing the hypotheses put forward by three language researchers: Kuno's Perceptual Difficulty Hypothesis (1974) which is based on the idea that centrally embedded RCs are more difficult to process due to the fickleness of the human memory system, Keenan's Relativized Subject Accessibility Hypothesis (1975) which posits that the head noun as a subject is easier to relativize than if it were an object; and Sheldon's Parallel Function Hypothesis (1974) which proposes that RCs sharing the same function as the head noun are easier to process. The findings of the study have shown that the acquisition rank order of the four types of RCs is OS > OO > SS > SO and that OS and OO types of RCs would be easier to acquire than SS and SO types. 
Gao (2014) conducts a study on the acquisition of RCs by a number of 40 Chinese-speaking learners. The purpose of the study is to test three different hypotheses: Keenan and Comrie's Noun Phrase Accessibility Hierarchy (NPAH). Kuno's Perceptual Difficulty Hypothesis (PDH) and Hamilton's Subject-Object Hierarchy Hypothsis (SOHH). The $\mathrm{SOHH}$ suggests that of the four types of clauses, the hierarchy in terms of the ease of acquisition is as follow: OS > OO/SS > SO where '>' implies 'easier to relativize' and '/' indicates 'as easy to relativize as'. Gao has adopted the same data elicitation tools as were previously employed by Izumi (2003): a Sentence Combination Test in conjunction with a Grammaticality Judgement Test in order to assess the participants' intuitive knowledge as well as their production of RCs. The results lend support only to Kuno's PDH (1974); however, the other two hypotheses are not borne out.

Alotaibi (2016) conducts a study that aims to investigate the learnability of English RCs by a number of 120 Kuwaiti EFL learners; 60 of which were Advanced Learners (ALS) and the other sixty were Intermediate Learners (ILS). More specifically, the purpose of the study is to examine the extent to which the participants are aware of the structure of RCs in English. The researcher employs a Sentence Combination Test as his elicitation tool. He concludes that though both groups have made several errors on the task, there is a clear distinction between the number of correct errors that the participants are able to produce and their proficiency level in English. The findings of the study have shown that the participants have made the least number of errors when asked to relativize the head noun in the subject position; therefore, supporting the normal acquisition hierarchy. Regarding the $\mathrm{SOHH}$, the results of the study have shown that the easiest type of RCs to relativize is OS. The researcher claims that this might be due to the fact that participants only needed to replace the head NP with the relative pronoun. In addition, he finds out that the most obvious type of error is in the unnecessary use of the resumptive pronoun which implies the negative transfer of L1.

In a more recent study, Khan \& Al-Namer (2017) have conducted a study to examine the extent to which 50 Arabic-speaking EFL learners 
comprehend RCs. The aim of the study is to test which relative pronoun among the seven pronouns is the most problematic and which is the easiest to comprehend. Moreover, it aims to measure whether the English proficiency level of the participants affects their performance on the test. The researcher has employed a multiple-choice test where the participants have been asked to choose the correct answer out of four choices. The results have shown that the participants may not be fully aware of English RCs. The t-test has shown that the English proficiency level affected the participants' performance on the test; i.e. there is a significant difference between the answers of the advanced learners and those of the intermediate learners. The results have also revealed that the easiest pronoun to comprehend is the pronoun when and the most difficult one is the pronoun whom.

\section{Methodology}

\subsection{Research Questions}

The study attempted to answer the following research questions:

1. What is the difficulty order of the four types of English restrictive RCs: SS, SO, OS and OO by Egyptian EFL learners?

2. To what extent do the results of the study lend support to any of the different hypotheses of RC acquisition: Relativized Subject Accessibility, Perceptual Difficulty Hypothesis, Parallel Function and Subject-Object Hierarchy Hypothesis?

3. What are the most marked errors made by Egyptian EFL learners in the acquisition of English restrictive RCs?

\subsection{Setting and Participants}

The study was conducted at the College of Language and Communication (CLC), Arab Academy for Science, Technology and Maritime Transport (AASTMT), Alexandria, in Miami Headquarters in October 2017. The participants are Egyptian first-year undergraduate students who are registered at the Department of Humanities in Term September 2017 before majoring in either Language and Translation or Media on starting their third term at the college. They learned EFL as a mandatory course for at least ten years. Participants' age ranged from 18 to 19 years old. Most of the participants were female $(n=56)$. Based 
on the results of the students' scores in a Placement Test given to nearly 90 students, 61 upper-intermediate to advanced students whose scores were above $50 \%$ in the Placement Test were selected as the sample group for this study. This sample of students was purposively selected since the grammatical construction under investigation is a complex one; therefore, an intermediate to advanced level of English language proficiency was considered a prerequisite for the selected participants in this study.

With these participants, two different research designs, each containing a different data collection instrument eliciting relative clauses, were tried out. The SCPT was chosen to elicit data on students' production whereas the GJT was chosen to get insights into what students think is correct without producing any sentences themselves or providing any corrections to incorrect sentences. The time given for the completion of the two tests was 25 minutes.

\subsection{Instruments}

The first data collection instrument was a SCPT (see Appendix A). In this task, the students were given 16 pairs of sentences and were then asked to combine these into sentences containing RCs. There were four sentences for each RC type under study. The task was chosen because it was productive in nature. In this task, students were expected to perform the following operations:

1. Identifying the co-referential noun/ pronoun in order to be able to form an accurate sentence in English.

2. Inserting one sentence into the other without violating the structure or the meaning of the sentence.

The distribution of the items in the SCPT with respect to the types of relative clauses they represent is demonstrated in Table 1.

Table 1: Item Distribution of the Four Types of RCs in the SCPT

\begin{tabular}{|c|c|c|c|c|}
\hline & SS & SO & OS & OO \\
\hline \multirow{2}{*}{ Items } & $1,5,10,13$ & $2,8,12,15$ & $3,6,9,14$ & $4,7,11,16$ \\
\hline
\end{tabular}


The second data collection instrument was a GJT (see Appendix B). According to Crystal, a GJT can be defined as "the conformity of a sentence, or part of a sentence, to the rules defined by a particular grammar of the language; also called well-formedness" (as cited in Baysal, 2000, p. 135). It is a test that assesses the students' intuition about what they think is grammatically acceptable in the target language. In this way, it is not production-based; it is rather directed towards understanding students' competence with the target structure. In the GJT, there were four sentences for each of the RC types: two grammatically correct and two incorrect. The random distribution of the items is shown in table 2 below.

Table 2: Item Distribution of the Four Types of RCs in the GJT

\begin{tabular}{|c|c|c|c|c|}
\hline & SS & SO & OS & 00 \\
\hline \multirow{2}{*}{ Items } & $1,5,10,13$ & $3,7,12,14$ & $4,6,8,16$ & $2,9,11,15$ \\
\hline
\end{tabular}

\subsection{Procedure (Scoring)}

In studies on the order of acquisition, the number of errors plays a significant role in determining the order of acquisition. Dualy, Burt and Krashen (as cited in Baysal, 2000, p. 136) have claimed that in acquisition order studies, $80 \%$ of correct responses are enough for a structure to be regarded as learned. However, the analysis in this study is based on the number of correct responses. Whereas all correct responses were counted as (1), an error is given a score of (0). In the two data collection instruments, there were four items for each of the RC types. As shown in Table 3, each type was elicited by a total of 8 items and a total of 4 items when considered separately.

Table 3: Total Number of Items According to Test

\begin{tabular}{|c|c|c|c|c|}
\hline & SS & SO & OS & OO \\
\hline SCPT & 4 & 4 & 4 & 4 \\
\hline GJT & 4 & 4 & 4 & 4 \\
\hline Total & 8 & 8 & 8 & 8 \\
\hline
\end{tabular}




\subsection{Statistical Analysis}

In each of the two tests, the SCPT and the GJT, the average of correct responses for the four items representing each of the four types of RCs was calculated. Accordingly, the difficulty order of the four types of RCs was calculated.

\section{Results}

In order to investigate the rank order of mastery over the four types of RCs: SS, SO, OS and OO, the raw scores and percentages of both the SCPT and the GJT were calculated and presented according to each of the four types of RCs.

\subsection{Sentence Combination Production Test (SCPT)}

As shown in Table 4, the difficulty order of the production of the four types of RCs for the target group in the SCPT was SS (65.6\%) $>$ OS $(63.1 \%)>$ OO $(55.7 \%)>$ SO $(41.8 \%)$ and that the easiest type for mastery in the target group was SS relative clause type while the most difficult type for mastery was SO relative clause type.

Table 4: Numbers and Percentages of Correct Responses of the Four Types of RCs in the SCPT

\begin{tabular}{|c|c|c|c|c|}
\hline \multicolumn{5}{|c|}{ Raw Scores (N = 976) } \\
\hline RC & $\begin{array}{c}\text { SS } \\
(n=244)\end{array}$ & $\begin{array}{c}\text { SO } \\
(n=244)\end{array}$ & $\begin{array}{c}\text { OS } \\
(n=244)\end{array}$ & $\begin{array}{c}\text { OO } \\
(n=244)\end{array}$ \\
\hline Mean & $(160)$ & $(102)$ & $(154)$ & $(136)$ \\
\hline Percentage & $65.6 \%$ & $41.8 \%$ & $63.1 \%$ & $55.7 \%$ \\
\hline
\end{tabular}

Note: ( $n=$ the total number of test items)

Raw scores: $(N=976)=$ SS $(n=244)+$ SO $(n=244)+$ OS $(n=244)$ $+O O(n=244)$ 


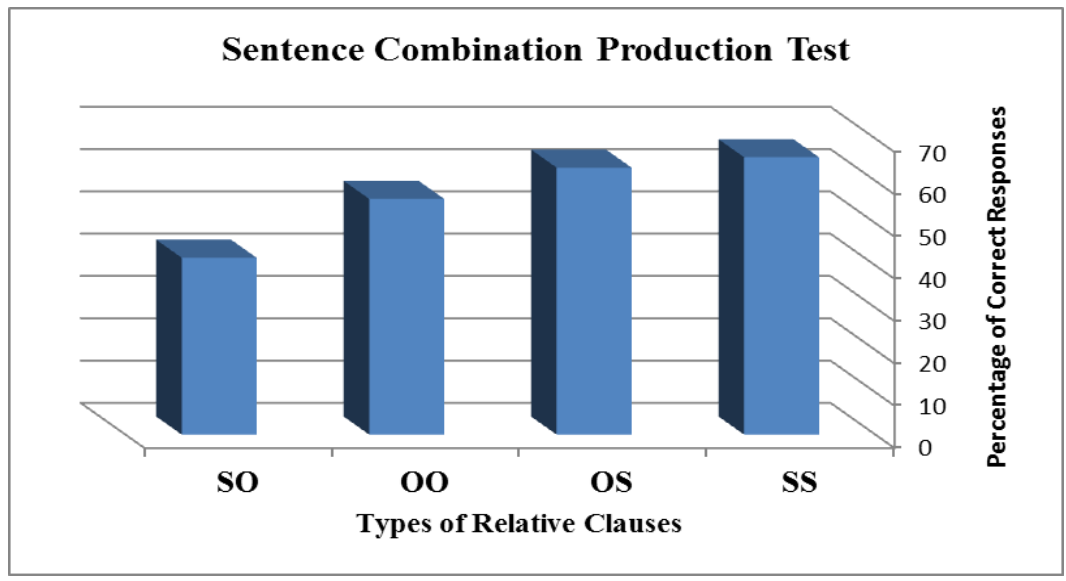

Figure 1: Percentage of Correct Responses for the Four Types of RCs in the SCPT

\subsection{Grammaticality Judgement Test (GJT)}

As shown in Table 5 below, the difficulty order of the recognition of the four types of RCs for the target group in the GJT was SS $(83.2 \%)>$ OS $(74.2 \%)>$ SO $(69.7 \%)>$ OO $(62.3 \%)$ and that the easiest type for mastery in the target group was SS relative clause type while the most difficult type for mastery was 00 relative clause type.

Table 5: Numbers and Percentages of Correct Responses for the Four Types of RCs in the GJT

\begin{tabular}{|lcccc|}
\hline \multicolumn{5}{c|}{ Raw Scores (N=976) } \\
\hline RC & $\begin{array}{c}\text { SS } \\
(n=244)\end{array}$ & $\begin{array}{c}\text { So } \\
(n=244)\end{array}$ & $\begin{array}{c}\text { OS } \\
(n=244)\end{array}$ & $\begin{array}{c}00 \\
(n=244)\end{array}$ \\
Mean & $(203)$ & $(170)$ & $(181)$ & $(152)$ \\
Percentage & $83.2 \%$ & $69.7 \%$ & $74.2 \%$ & $62.3 \%$ \\
\hline
\end{tabular}

Note: ( $n=$ the total number of test items)

Raw scores: $(N=976)=$ SS $(n=244)+$ SO $(n=244)+$ OS $(n=244)$ $+O O(n=244)$ 


\section{Grammaticality Judgement Test}

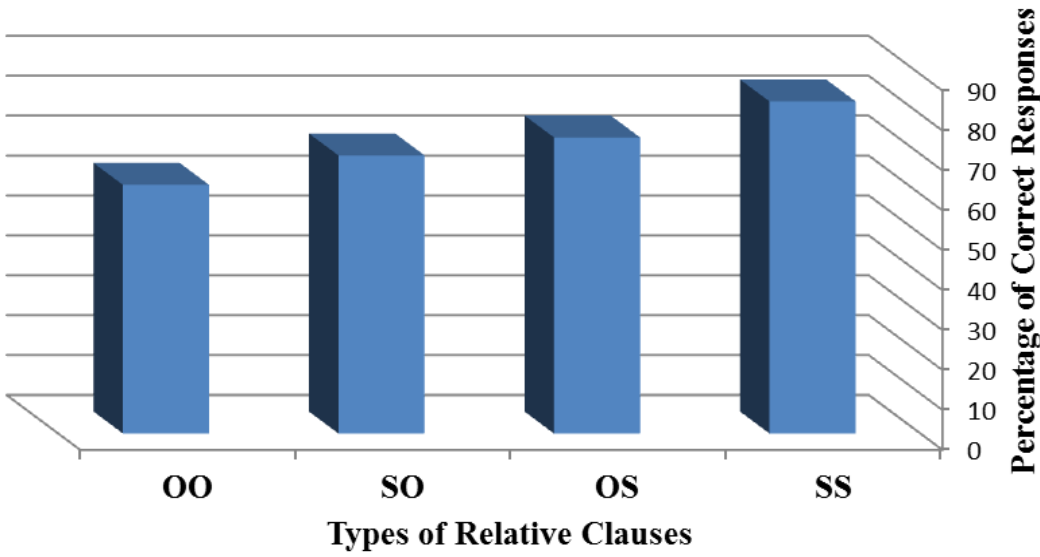

Figure 2: Percentage of Correct Responses for the Four Types of RCs in the GJT

\section{Discussion}

The findings of the study have revealed that Egyptian adult EFL learners are not fully aware of the structure of RCs. Though their performance in the GJT, where the total average of correct responses was $72.4 \%$, revealed much better results than the SCPT where the total average of correct responses was $56.6 \%$, still they are not in good command of this complex grammatical structure.

As previously shown, the data in both tests given to the target group were analyzed with the frequency count of the four types of RCs and were put into four different categories. The results show that, for Egyptian EFL learners, SS and OS types of RCS are easier than OS and OO types.

The data were checked against the acquisition hypotheses put forward by four different researchers. Accordingly, the following results were produced:

- Keenan (1975) asserted that relativized subjects are more accessible than relativized objects and, therefore, SS and OS types should be easier than SO and OO types. In the SCPT, SS + OS = $160+$ $154=314$ while $\mathrm{OO}$ and SO=102 $+136=208$. In the GJT, SS + OS = 
$203+181=384$ while $\mathrm{OO}$ and $\mathrm{SO}=170+152=322$. The data seem to fully support this hypothesis.

- Kuno (1975) argued that center embedding is perceptually difficult and, therefore, OS and OO types would be easier than SS and SO. Referring to the data, in the SCPT, OS + OO = 154 + 136 = 290 while $\mathrm{SS}+\mathrm{SO}=160+102=262 . \mathrm{In}$ the GJT, OS $+\mathrm{OO}=181+152=333$ while SS + SO $=203+170=373$. The data from the SCPT fully support Kuno's hypothesis while the data from the GJT partially support this hypothesis.

- Sheldon (1974) claimed the parallel function hypothesis which asserts that RCs easiest to acquire are those in which the relative pronoun has the same function as the head noun. It follows that SS and $\mathrm{OO}$ types are expected to be easier than $\mathrm{SO}$ and OS types. In the SCPT, SS $+O O=160+136=296$, while SO $+O S=154+102=256$. In the GJT, SS $+\mathrm{OO}=203+152=355$, while SO $+\mathrm{OS}=181+170=$ 351. Thus, the data in this study fully support Sheldon's hypothesis.

- Hamilton's (1994) SOHH posits that the OS type should be the easiest to acquire since it contains only one discontinuity. $\mathrm{OO}$ and SS types are of equal difficulty since they contain two discontinuities. SO type is assumed to be the most difficult since it contains three discontinuities. In this study, in both the SCPT and the GJT, neither the OS type is the easiest to acquire nor SO type is the most difficult to acquire. Furthermore, $\mathrm{OO}$ and SS types proved to be of unequal difficulty. Thus the findings of the study did not lend any support to this hypothesis.

Concerning Research question 1: "What is the difficulty order of the four types of English RCs: SS, SO, OS and OO by Egyptian EFL learners?", the difficulty order of RCs in the SCPT is as follows:

$$
\mathrm{SS}>\mathrm{OS}>\mathrm{OO}>\mathrm{SO}
$$


And in the GJT, the order of difficulty is as follows:

$$
\mathrm{SS}>\mathrm{OS}>\mathrm{SO}>\mathrm{OO}
$$

Then it can be concluded that, for Egyptian learners, the SS and OS types of RCs are considered easier to acquire than $\mathrm{OO}$ and SO.

Regarding Research question 2: "To what extent do the results of the study lend support to any of the different hypotheses of RC acquisition: Relativized Subject Accessibility, Perceptual Difficulty Hypothesis, Parallel Function and Subject-Object Hierarchy Hypothesis?", on the one hand, the results of the study fully support Keenan's Relativized Subject Accessibility (1975), Sheldon's Parallel Function Hypothesis (1974) and partially support Kuno's Perceptual Difficulty Hypothesis (1975). On the other hand, the result do not lend any support to Hamilton's (1994) SOHH hypothesis.

With regard to Research question 3: "What are the most marked errors made by Egyptian EFL learners in the acquisition of English Restrictive RCs?", through analyzing the responses of the participants in the SCPT, the most marked errors are: incorrect positioning of RCs, the choice of wrong relative pronouns, maintaining resumptive pronouns, maintaining both relative pronouns and subject pronouns and, finally, problems with genitive and indirect object types of RCs. These can be outlined and further explained as follows:

1. Incorrect positioning of RCs. Examples of the participants' incorrect responses are:

(1) *The taxi driver was friendly who took me to the airport. (Correction: The taxi driver who took me to the airport was friendly.)

(2) *The man is standing over there that Ann brought him to the party. (Correction: The man that Ann brought to the party is standing over there.)

(3) * The man called the police whose wallet was stolen.

(Correction: The man whose wallet was stolen called the police.) 
(4) * The candidate didn't win the election whom I voted for her.

(Correction: The candidate whom I voted for didn't win the election.)

(5) * The vase broke in half which fell on the floor.

(Correction: The vase which fell on the floor broke in half.)

(6) * The picture was beautiful which she was looking at.

(Correction: The picture which she was looking at was beautiful.)

(7) * The flowers were growing in the park which the old man picked.

(Correction: The flowers which the old man picked were growing in the park.)

(8) * The film was directed by David Lean which Mary had seen in Venice.

(Correction: The film which Mary had seen in Venice was directed by David Lean.)

In these examples, the RCs do not immediately follow the nouns or noun phrases they modify; therefore, these were marked as wrong responses. For instance, in example (1), the RC 'who took me to the airport' should come immediately after the noun phrase, 'the taxi driver', that it modifies. In example (3), the RC 'whose wallet was stolen' should come immediately after the noun phrase it modifies: 'The man'. In example (7), The RC 'which the man picked' should immediately follow the noun phrase that it modifies: 'The flowers'.

2. The choice of wrong relative pronouns. Following are illustrative examples of the participants' incorrect responses in relation to this error:

(9) * The taxi driver whom took me to the airport was friendly. (Correction: 'who' instead of 'whom')

(10) * The man whose Ann brought to the party is standing over there. (Correction: 'who/whom' instead of 'whose')

(11) * I must thank the people whose I got a present from. (Correction: 'who/ whom' instead of 'whose') 
(12) * The man whom wallet was stolen called the police.

(Correction: 'whose' instead of 'whom')

(13) * I always visit the child which I told my life story to (Correction: 'who/ whom' instead of 'which')

$(14)$ * The candidate which I voted for didn't win the election.

(Correction: 'who/ whom' instead of 'which')

(15) * John telephoned the girl whose sold a car yesterday.

(Correction: 'who' instead of 'whose')

$(16) *$ Olga wrote on a topic who she didn't know anything about.

(Correction: 'which' instead of 'who')

(17) * The child ate the cookies whom the neighbors baked.

(Correction: 'which' instead of 'whom')

In the aforementioned examples, it is evident that Egyptian EFL learners are sometimes confused regarding the differences in meaning between various types of relative pronouns. For instance, they sometimes mistakenly replace 'whom', a direct object pronoun, by 'who', a subject pronoun, as in "The taxi driver whom took me to the airport was friendly" (example 9), or 'whose', a possessive pronoun, by 'whom', a direct object pronoun, as in "The man whom wallet was stolen called the police." (example 12).

3. Maintaining resumptive pronouns. Examples of incorrect responses by the participants with regard to this error are:

(18) * The man who Ann brought him to the party is standing over there.

(Correction: 'him' must be omitted)

(19) * I must thank the people who I got a present from them.

(Correction: 'them' must be omitted)

(20) * The candidate that I voted for her didn't win the election. (Correction: 'her' must be omitted) 
(21) * Olga wrote on a topic that she knew nothing about it. (Correction: 'it' must be omitted)

(22) * The picture which she was looking at it was beautiful. (Correction: 'it' must be omitted)

This clearly indicates the negative transfer of L1. Resumptive pronouns are considered a major feature of RCs in Arabic. The Longman Dictionary of Language Teaching and Applied Linguistics (2010) defines resumptive pronouns as "in the position of a trace left behind when forming a wh-phrase. [...] Resumptive pronouns are ungrammatical in Standard English, but they are acceptable or obligatory in many languages (e.g. Arabic)" (as cited in Alroudhan, 2016, p. 36). The resumptive pronoun is known as الضـمير العائـد in Arabic. This resumptive pronoun functions as a referent for the head noun and is usually attached to a verb. The resumptive pronoun agrees with the head noun in number, gender and case (Alroudhan, 2016). Following is an illustrative example:

I saw the message that the student wrote

-

Due to the negative transfer of $L 1$, the participants incorrectly produced sentences such as "The man who Ann brought him to the party is standing over there" (example 18) where the pronoun 'him' should not be retained or "Olga wrote on a topic that she knew nothing about it" (example 21) where the pronoun 'it' should not be kept.

4. Maintaining both relative pronouns and subject pronouns. Following are illustrative examples of the participants' incorrect responses in the SCPT with regard to this error:

(23) *Algebra problems contain letters which they stand for unknown numbers.

(Correction: 'they' must be omitted)

(24) * She was looking at a picture which it was beautiful.

(Correction: 'it' must be omitted) 
(25) *The old man picked some flowers which they were growing in the park.

(Correction: 'they' must beomitted)

In these examples, the participants sometimes mistakenly keep both the relative pronoun (e.g. which) and the subject of the subordinate clause (e.g. they; it) where the latter must be omitted.

5. Problems with genitive and indirect object types of RCs.

Following are illustrative examples of the participants' erroneous responses in the SCPT in relation to such types of RCs:

(26) * I live in a dormitory which its residents came from different countries.

(Correction: I live in a dormitory whose residents come from different countries.)

$(27)^{*}$ The dormitory which I live in its residents came from different countries.

(Correction: I live in a dormitory whose residents come from different countries.)

(28) * The man called the police his wallet was stolen.

(Correction: The man whose wallet was stolen called the police.)

(29) * The man who whose wallet was stolen called the police.

(Correction: The man whose wallet was stolen called the police.)

(30) * I always visit the child whom I told my life story.

(Correction: I always visit the child whom I told my life story to.)

These examples illustrate that participants are sometimes unaware of the correct structure of genitive clauses. Instead of using the relative pronoun "whose", they use "which its": a relative pronoun and a possessive pronoun or "who whose": two relative pronouns. They might also be facing difficulty in forming indirect object RCs. For instance, in example (30), the preposition 'to' should have been retained at the end of the RC 'whom I told my life'. 


\section{Conclusion}

This study aimed at examining the acquisition order of English restrictive RCs by Egyptian EFL learners using a SCPT in conjunction with a GJT. It further investigated the extent to which the results of the study are in agreement with any of the hypotheses of RC acquisition. Findings of the study revealed that Egyptian learners may not be fully aware of the different syntactic structures of RCs. For Egyptian learners, SS and OS would be much easier to acquire than OS and OO types of RCs. Furthermore, these results lend full support to two hypotheses: Relativized Subject Accessibility and Parallel Function, and partial support to Perceptual Difficulty Hypothesis and are, therefore, inconsistent with the Subject-Object Hierarchy Hypothesis.

This study may contribute to the literature on the acquisition of $\mathrm{RCs}$. The results of the study clearly reveal the complexity of the RC as a grammatical structure. Egyptian EFL learners are not fully aware of this structure since their performance in each of the tests employed in the study (SCPT and GJT) was below $80 \%$. It is worth noting here that in acquisition order studies, $80 \%$ of correct responses are enough for a structure to be regarded as learned (Baysal, 2000). In this study, OO and OS are the most difficult types of $\mathrm{RCs}$ to be acquired by Egyptian learners. The most common errors are the incorrect positioning of RCs, the wrong use of the relative pronoun and the unnecessary maintaining of resumptive pronouns which indicate the negative transfer of $L 1$. In addition to these, other errors included problems with genitive clauses and the omission of the preposition with the relative pronoun whom.

Through analyzing the performance of the participants and the errors they commonly made in the two tests employed by the researcher in this study, there arise a number of pedagogical implications. Language teachers need to be aware of the most difficult RCs for Egyptian learners and the most marked errors made by Egyptian learners in particular. Taking the results of this study into 
consideration, it is recommended that ESL/ EFL teachers need to acquaint the learners with the different types of RCs and the rules of their formation. As far as materials design and lesson plans are concerned, more emphasis is to be given to OO and OS types of RCs since these proved to be more difficult than SO and SS types for Egyptian EFL learners. Furthermore, learners can be given practice activities where they have sufficient opportunities not only to judge the grammaticality of sentences including RCs but also to produce different types of RCs correctly. In addition, they should be given continuous feedback by their teachers for the purpose of gradually producing error-free sentences including RCs. In brief, the results of the study can inform curriculum design, teaching methodology and evaluation for Egyptian EFL learners.

Finally, it can be concluded that since the findings of this study are inconsistent with the findings of similar previous studies on Arabspeaking EFL Learners (e.g. Alotaibi, 2016) which reveal that the OS and $\mathrm{OO}$ types of RCS are easier than SO and SS, there is need for further research on the acquisition order of RCs by Arab-speaking EFL learners in order to obtain deeper insights into the problems that EFL learners encounter when they acquire this complex grammatical construction. 


\section{References}


1. Abdolmanafi, S. J., \& Rahmani, Z. (2012). An Investigation of the Learnability of

Relative Clauses by EFL Learners. World, 2(3), 29-37.

Retrieved from

file://C:/Users/Hello/Downloads/1822-5733-1-M\%20(1).pdf

2. Alotaibi, A. M. (2016). Examining the Learnability of English

Relative Clauses: Evidence from Kuwaiti EFL Learners. English Language Teaching, 9(2). 57-65.

Retrieved from file:///C:/Users/Hello/Downloads/56219195616-1-SM.pdf

3. Alroudhan, H. E. (2016). The Acquisition of English Restrictive Relative Clauses by Arab Adult EFL Learners. Advances in Language and Literary Studies, 7(1), 33-53.

Retrieved from

http://www.journals.aiac.org.au/index.php/alls/article/view/ $\underline{1986 / 1797}$

4. Baysal, A. (2000). A Study on Restrictive Relative Clauses with Particular Reference to Data Triangulation in ELT Research. Sosyal Bilimler Dergisi, 129-146.

Retrieved from

https://earsiv.anadolu.edu.tr/xmlui/bitstream/handle/11421/ 528/153751.pdf?sequence=1\&isAllowed $=y$

5. Chang, Y. (2004). Second Language Relative Clause Acquisition: An Examination of Cross-Linguistic Influences. National Chung Hsing University.

Retrieved from https://www.researchgate.net/publication/234586883 Secon d Language Relative Clause Acquisition An Examination of Cross-Linguistic Influences

6. Diessel, H. \& Tomasello, M. (2005). A New Look at the Acquisition of Relative Clauses. Language, 81(4), 882-906. Retrieved from 
http://www.eva.mpg.de/documents/Linguistic\%20Society\%2 0of\%20America,\%20MUSE/Diessel New Language 2005155 5274.pdf

7. Gao, Q. Q. (2014). Chinese EFL Learners' Acquisition of English Relative Clauses. International Journal of English Linguistics, 4(3), 82-87. Retrieved from file:///C:/Users/Hello/Downloads/37371-126846-1-SM.pdf

8. Hamilton, R. I. (1994). Is Implicational Generalization Unidimensional and Maximal? Language Learning, 44, 123157. Retrieved from http://dx.doi.org/10.1111/j.1467-1770.1994.tb01096.x

9. Keenan, E.L. (1975). Variation in Universal Grammar. In Fasold and R. Shuy (eds.),Analyzing Variation in Language. Wahington DC: Georgetown University Press.

10. Keenan, E. L., \& Comrie, B. (1977). Noun Phrase Accessibility and Universal Grammar. Linguistic Inquiry, 5(1), 117-136. Retrieved from http://citeseerx.ist.psu.edu/viewdoc/download?doi=10.1.1.4 63.2048\&rep=rep1\&type $=$ pdf

11. Kuno, S. (1974). The Position of Relative Clauses and Conjunctions. Linguistic Inquiry, 5, 117-136.

12. Khan, S. S. \& Al-Namer, L. (2017). The Comprehension of English Relative Clauses by Arabic-Speaking EFL Learners. International Journal of Education, 9(1), 192- 207.

DOI: 10.5296/ije.v9il.11025.

13. Sheldon, A. (1974). The Role of Parallel Function in the Acquisition of Relative Clauses in English. Journal of Verbal Learning and Verbal Behaviour, 3, 271-281.

14. Suh, J. S. (2000). A Difficulty Ordering for the Learning of English Relative Clauses. The Journal of English Grammar, 4, 5-22.

Retrieved from

file:///C:/Users/Hello/Downloads/ieg-4-1-1\%20(1).pdf 
Appendix A:

Sentence Combination Production Test (SCPT)

Name:

Class:

Mark in Placement Test: ........... 


\section{Please combine each of the following pairs of sentences using relative clauses. Use who, which, that, whose and whom.}

1. The taxi driver was friendly. He took me to the airport.

2. The man is standing over there. Ann brought him to the party.

3. Algebra problems contain letters. They stand for unknown numbers.

4. I must thank the people. I got a present from them.

5. The man called the police. His wallet was stolen.

6. I live in a dormitory. Its residents came from different countries.

7. I always visit the child. I told my life story to the child.

8. The candidate didn't win the election. I voted for her.

9. John telephoned the girl. The girl sold a car yesterday.

एะ. 


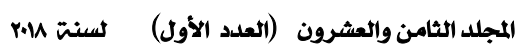

10. The vase broke in half. The vase fell on the floor.

11. Olga wrote on a topic. She knew nothing about it.

12. The picture was beautiful. She was looking at it.

13. The house has a green door. The house stands on the river.

14. The old man picked some flowers. Some flowers were growing in the park.

15. The film was directed by David Lean. Mary had seen it in Venice.

16. The child ate the cookies. The neighbors baked the cookies.

\section{Appendix B:}

\section{Grammaticality Judgement Test (GJT)}

Name:

Class:

Indicate whether the following sentences are grammatical or ungrammatical. If you think that the sentence is grammatical, put a 
tick; if you think the sentence is ungrammatical, put a cross $(X)$ in the blanks provided. Please do not make any corrections.

1. The woman which dress was torn got very upset.

2. The little boy wanted the chair which I was keeping my books under it.

3. The person which Mary spoke to took my message.

4. Jane helped the boy who tried to solve the problem.

5. Our neighbor's son who had broken our window did not apologize.

6. Jane discussed with the woman whom child had stolen her bag.

7. The man whom you spoke with was the principal.

8. John read the magazine which had scientific information.

9. I saw the bank manager to who I gave my cheque.

10. The girl who she had disappeared suddenly could not be found.

11. I found the taxi in which I forgot my purse.

12. The homework which our teacher had assigned it was very difficult.

13. The journalist whose interview I watched yesterday has a programme on 


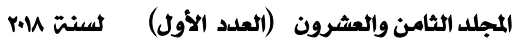

TV.

14. The book which I borrowed from the library is now out of print.

15. The child ate a sandwich which his mother made at home.

16. I bought a wonderful car which it is right at the corner. 